\title{
Journal of Individual Differences in Education
}

\section{Primary School Students' Perceptions about Robotic Coding}

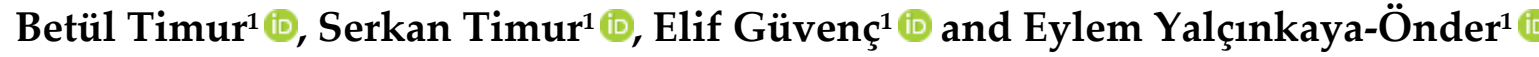

${ }^{1}$ Çanakkale Onsekiz Mart University, Çanakkale, Turkey

\begin{tabular}{l}
\hline A B S TRACT \\
The purpose of this study was to examine $7-9$ years old students' \\
perceptions of robotic coding through drawings and their explanations. \\
Phenomenological research design, one of the qualitative research methods \\
and techniques, was used. Convenience sampling method was used in this \\
study. A total of 14 students who took education about robotic coding \\
education in a private school in a city center in the Marmara region \\
participated in the study. "Draw and explain technique" was used in the \\
collection of the data. The collected data were analyzed using descriptive \\
analysis. The results of the study indicated that, students mostly drew \\
robots in their drawings regarding the concept of robotic coding. In \\
addition to drawing robots, they drew tablets, 3D-printers, cars, \\
computers, headphone and Arduino set, respectively. Most of the students \\
drew inanimate objects such as "robot" and "3D-printer" in their drawings, \\
and only a few included living beings to their drawings. While it was seen \\
that most of the students did not include themselves in their drawings, it \\
was also noteworthy that they added living features such as human, face \\
and hand to the robots or devices they drew. Moreover, it was observed \\
that girls used colors more than boys in their drawings.
\end{tabular}

ARTICLE INFO

Article History:

Received:16.06.2021

Received in revised form:27.06.2021

Accepted:28.06.2021

Available online:30.06.2021

Article Type: Standard Paper

Keywords: Robotic coding, 3D-design, draw and explain technique, primary school.

\section{Introduction}

At a time when new technologies have a significant impact on human life and a big part of education, so it is important to start digital literacy education at an early age. This is especially true for "new" coding literacy. In the field of robotics, the terms "coding" and "programming" can sound intimidating and even confusing to some early years' practitioners but there is really no difference between the two terms, both actually mean entering instructions into a machine or robot. Robotics is the design, construction, operation and application of robots in society. In the early years, robotics tends to focus on how robots move and how they react to children's sensory input. The sensory direction or command input of kids to the robot is an example of digital literacy of coding (Campbell \& Walsh, 2017).

According to Ulubey and Aykaç (2017), 21 $1^{\text {st }}$ century citizens are individuals who have the ability to think critically, have high creativity and use technology effectively and accurately. With the advancement of technology and the development of technological devices to be used in education, the use of technology in education has increased. In recent years, it has been observed that updates have been made in educational programs and the number of alternative methods in teaching environments has increased (Çağıltay, Çakıroğlu, Çağıltay \& Çakıroğlu, 2001). 
With the introduction of technology in educational environments, studies are carried out to improve and develop coding skills in educational programs (Atalay, Anagün, \& Kumtepe, 2016; Sayın \& Seferoğlu, 2016). The concepts of coding, robotics, 3D-design production and 3D-printers, which are increasingly important today and supporting children's creativity and productivity, are prominent in education. In the last few years, the integration of coding activities for children into K-12 education has improved. Robotic coding has also become an integral part of school curricula in many countries in education (Papavlasopoulou, Giannakos and Jaccheri, 2019).

\subsection{Theoretical Framework and Literature Review}

Educational robotics is a transformational tool for learning, computational thinking, coding and engineering, all of which are increasingly seen as important components of STEM learning in K-12 education. Despite the fact that robotics in education for school-age children has existed since the late 1900s and has become more popular among young students, it is not well integrated as a technological learning tool in regular school settings. Learning with the educational robot offers students the opportunity to question and think about technology. When students design, build, program, and document robots, they learn how technology works and apply the skills and content knowledge learned at school in a meaningful and exciting way. Educational robots are rich with opportunities to integrate not only STEM, but also many disciplines including literacy, social studies, dance, music and art. It gives students the opportunity to find new ways to work together to improve their collaboration skills, express themselves using technological tools, solve problems, and think critically and creatively. Educational robots are a learning tool that enhances the student experience through hands-on mind learning. Robotics provides a hands-on method to teach thinking skills and science process skills through technological design and computer programming activities involved in any robot project (Sullivan, 2008). Robotic activity is an effective teaching strategy to increase interest in robotics, increase self-efficacy to teach with robotics, improve understanding of science concepts and promote the development of computational thinking skills (Jaipal-Jamani \& Angeli, 2017). Furthermore, they provide a fun and exciting learning environment due to its practical nature and integration of technology. The engaging learning environment motivates students to learn all the skills and knowledge they need to reach their goals to complete projects that interest them (Eguchi, 2014). Despite the difficulties in classroom practices, STEM integrated approach to educational coding and robotics are beneficial in primary education for both students and teachers in improving the teachinglearning process (García-Carrillo, Greca and Fernández-Hawrylak, 2021). Exploring with and using the robot kits, and activities, helps the teachers build their confidence and knowledge to present their students to computational thinking (Chalmers, 2018).

In primary education, visual block programming and robotics improves the the understanding of basic computational concepts such as sequences, loops, conditional statements, parallel execution, event handling and use of robotics. Improvements were also noted in didactic interaction, and in greater enjoyment, enthusiasm, efficiency and active participation of students (López, Otero, and García-Cervigón, 2021). Furthermore, Sáez-López, Sevillano-García and Vazquez-Cano (2019) investigated the effect of programming on primary school students' mathematical and scientific understanding. Gaining a high degree of student engagement and engagement as well as an understanding of computational concepts emphasized the importance of the effectiveness of introducing robotics and visual programming based on active methodologies in primary education. Implementation of this design enabled sixth grade primary school students to understand coding, motion, engines, sequences and conditionals through activities that integrate programming and robotics in science and mathematics. Programming and robotics are integrated into one didactic unit of mathematics and another unit of science. Statistically significant improvements have been achieved in the understanding of mathematical concepts and the acquisition of computational concepts based on an active pedagogical practice that instills motivation, enthusiasm, commitment, fun, and interest in the studied content. 
It was noted that many elementary students have limited programming experience (Chen et al., 2017). Although robotic coding education is given in some private institutions in Turkey, it has not been included in the education curriculum yet. Giving this education at an early age and determining its effectiveness have been demonstrated by many studies. Therefore, determining the perceptions of students who have previously received training on robotic coding would not only evaluate the reflections of the education they have received, but would contribute to future studies and the relevant curriculum on this subject.

The research was guided by the following questions:

- What are primary school students' perceptions about robotic coding?

- Do primary school students' robotic coding perceptions differ by gender?

\section{Method}

\subsection{Research Design}

Phenomenological research design, one of the qualitative research methods, was used in the research. In order to determine the robotic coding perceptions of students, "draw and explain technique" was used. This technique is used to understand how children construct their thoughts and concepts in their minds (McWhirter, Collins, Bryant, Wetton, \& Bishop, 2000). The collected data were analyzed using descriptive analysis.

\subsection{Study Group}

The study group of the study consisted of 14 students who took robotic coding education in a private school in a city center in the Marmara region in the 2019-2020 academic year. Study group students studying in a private institution participated in many coding-related activities by taking months-long robotic coding training. They used the scratch junior program in these trainings. In addition, robotic coding training also covered activities such as teaching algorithms, making simple electric giants with Arduino sets, and building circuits. In addition, they had the opportunity to make some objects with a 3D pen printer during their robotic coding training. Demographic characteristics of students was given in Table 1.

Table 1. Demographic characteristics of students

\begin{tabular}{llcc}
\hline Demographic Characteristics & & $\mathrm{f}$ & $\%$ \\
\hline Gender & Boy & 10 & 71.4 \\
& Girl & 4 & 28.6 \\
Socio-Economic Status & Low & & \\
& Middle & 7 & 50.0 \\
& High & 7 & 50.0 \\
& & 0 & 0.00 \\
Father Profession & Public employee & 4 & 28.6 \\
& Private sector & 2 & 14.3 \\
& Worker & 1 & 7.10 \\
& Not working & 0 & 0.00 \\
& Other & 7 & 50.0 \\
Mother Profession & & & \\
& Public employee & 6 & 42.9 \\
& Private sector & 0 & 0.00 \\
& Worker & 2 & 14.3 \\
& Not working & 6 & 42.9 \\
& Other & 0 & 0.00 \\
\hline Total & & & 100 \\
\hline
\end{tabular}


Table 1 indicated that the majority of the students participating in the study were male students (71.4\%). The socio-economic level of these students was determined in the middle and low categories. It is also seen that the fathers of nearly half of the students work in jobs other than the public and private sectors, and the mothers of half of them do not work in any job.

\subsection{Data Collection Tools}

In the current study, students were asked to drawings reflecting their thoughts about the concept of robotic coding on drawing paper. The back side of the drawing paper used was left blank by the teacher to write student comments. The purpose of using this technique is to reveal the ideas, knowledge and thoughts that the student cannot express without limiting herself to words (White \& Gunstone, 1992). For this reason, drawing-writing technique, in which drawings and explanations are used together, is frequently encountered in the literature to reveal individuals' ideas and opinions about the concept.

\subsection{Data Collection Process}

In this study, drawing papers was distributed to the students, and they were asked to describe their thoughts about the concept of robotic coding through drawings. Students were not limited to the drawing paper, pencils and crayons they used. Each student was given about 15-20 minutes to make their drawings and about 10 minutes for their explanations. The teacher noted the students' explanations on the back of the drawing papers both because some of the students were in the literacy age and to prevent misinterpretation of student drawings.

\subsection{Data Analysis}

In the analysis of data, a descriptive analysis was used. Descriptive statistics provided frequency tables and the distribution of the variables. Researchers of the study analyzed and coded the robotic coding data. After coding, the related codes were then collected under appropriate themes. For reliability analysis, $25 \%$ of the data were analyzed by independent researchers (science education specialists). Thereafter, the reliability value was calculated as .90 according to Miles and Huberman (1994) consensus disagreement formula.

\section{Results}

The qualitative analysis of the students' answers to their drawings was presented and some samples selected from their drawings were included in this section. Students were asked to draw whatever came to their minds about "robotic coding". In line with the answers given by the students about robotic coding, two themes were determined as technological devices and production. In Table 2, it was noteworthy that most of the students drew robots as technological tools in their drawings.

Table 2. Distribution of themes and codes for students' robotic coding drawings

\begin{tabular}{lccc}
\hline Themes & Code & f & \% \\
\hline Technological Devices & Robot & 11 & 78.6 \\
& Tablet & 4 & 28.6 \\
Car & 3 & 21.4 \\
& Computer & 3 & 21.4 \\
& Headphone & 1 & 7.14 \\
Production & & & \\
& 3D-printer & 4 & 28.6 \\
& Arduino set & 1 & 7.14 \\
\hline
\end{tabular}

As can be seen in Table 2, the vast majority of students $(78.6 \%)$ drew robots when robotic coding was mentioned, it followed by tablet $(28.6 \%)$, 3D-printer $(28.6 \%)$, car $(21.4 \%)$, computer $(21.4 \%)$, headphone (7.14\%), and Arduino set (7.14\%). In addition, it was also examined whether the students drew themselves in their drawings and the answers related to this were presented in Table 3. 
Table 3. Distribution of students according to whether or not they include themselves in their drawings

\begin{tabular}{lcc}
\hline $\begin{array}{l}\text { Whether or not they include themselves in } \\
\text { their drawings }\end{array}$ & $\mathbf{f}$ & $\mathbf{\%}$ \\
\hline No & 12 & 80 \\
Yes & 2 & 20 \\
\hline Total & 14 & 100 \\
\hline
\end{tabular}

Most of the students (80\%) did not include themselves in their robotic coding drawings. The drawing below shows a student's view of robotic coding, with an explanation of it in the note below the drawing (Figure 1).

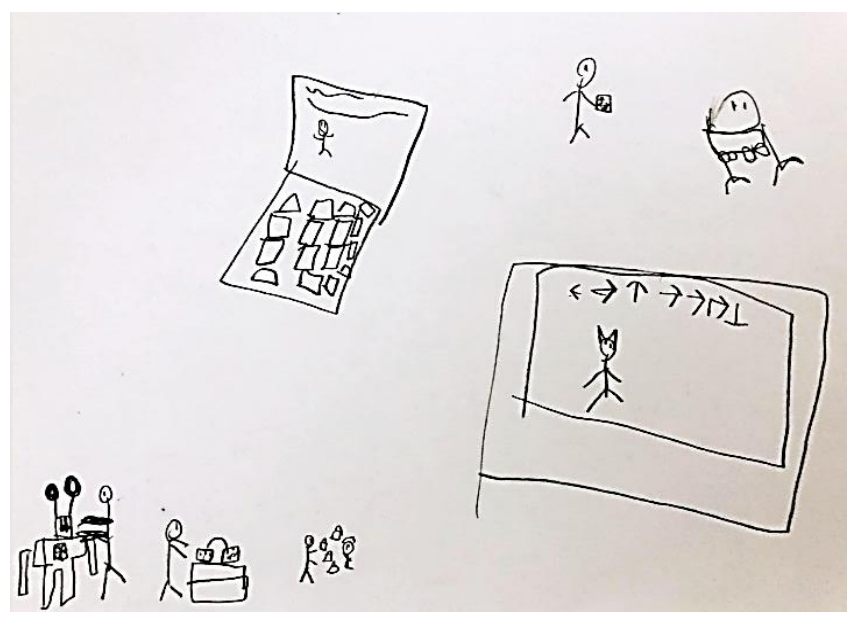

Figure 1. "... I build a robot with robotic coding,...I manufacture parts with a 3D printer..., I control the robots I have produced by coding on the tablet,...I control the robot with my tablet,...I sell what I have done to other people." (Boy, Age:8).

When the gender distribution of the students who included their own figures in their drawings was examined, it was noticed that none of the students, except for two male students, described themselves as a part of their drawings. The drawing with an explanation of a student who included himself in the picture was presented below as an example (Figure 2).

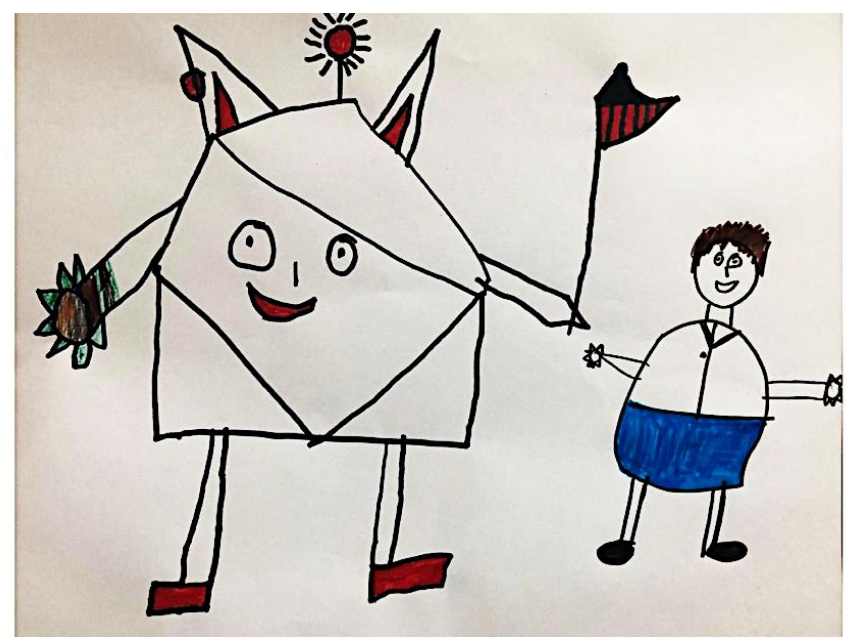

Figure 2. “...I made a robot and I have it as well. My robot can fly and make games. He has a game flag in his hand and starts the game. He has ears on his head, he hears very well, and he has a lamp on his head, he can see it in the dark..." (Boy, Age:8). 
Table 4. Distribution of students according to their "drawing another human being or living/nonliving things" in their drawings

\begin{tabular}{llcccc}
\hline Theme & Code & \multicolumn{3}{c}{ Boy } & \multicolumn{2}{c}{ Girl } \\
\cline { 3 - 6 } & & f & \% & f & \% \\
\hline \multirow{4}{*}{ Non-Living } & Robot & 8 & 80.0 & 3 & 75.0 \\
& Tablet & 3 & 30.0 & 1 & 25.0 \\
& Computer & 3 & 30.0 & 0 & 00.0 \\
& 3D-printer & 3 & 30.0 & 1 & 25.0 \\
& Car & 2 & 20.0 & 1 & 25.0 \\
& Headphones & 1 & 10.0 & 0 & 00.0 \\
& Arduino set & 0 & 00.0 & 1 & 25.0 \\
\hline Living & Human & 1 & 10.0 & 0 & 00.0 \\
\hline Total & & & 100 & & 100 \\
\hline
\end{tabular}

When Table 4 was examined, it was seen that only one student drew a human figure except for himself/herself in their drawings regarding robotic coding. Regarding the concept of robotic coding, majority of the girls and boys (75-80\%) drew robots, and approximately $25-30 \%$ of them drew tablet, $3 \mathrm{D}$-printer and car. Moreover, while some boys draw computer $(30 \%)$ and headphone $(10 \%)$ in their drawings, none of the girls drew these items. In addition, it was determined that $25 \%$ of the girls drew the Arduino set, while none of the boys did. Figure 3 and Figure 4 were the examples of students drawings and their views about them.
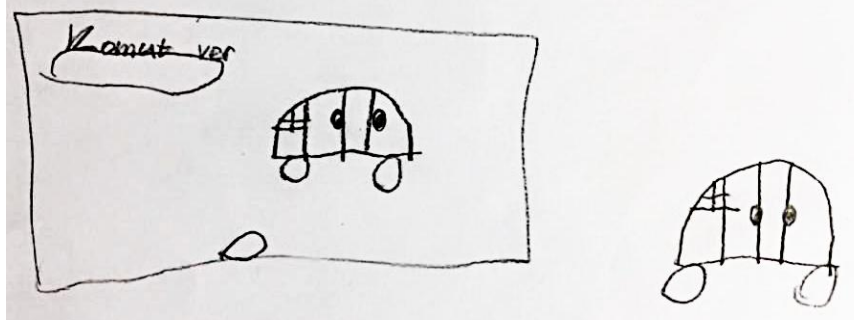

Figure 3. "The robot is moving with the encodings according to inputs on my tablet.." (Boy, Age:8).

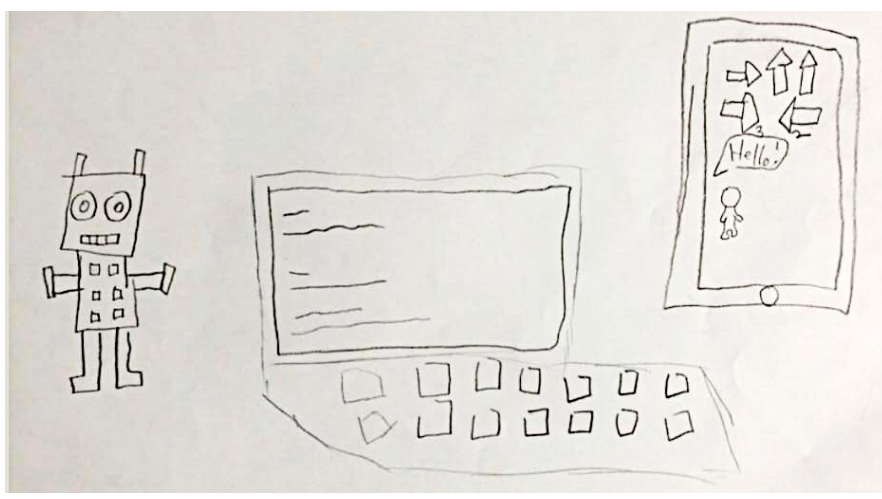

Figure 4. "I control the robot with my tablet and computer. I drag the codes on the tablet and the robot is moving..." (Boy, Age:8).

Table 5 demonstrates the distribution of what students draw in their drawings by gender. 
Table 5. Distribution of what students draw in their drawings by gender

\begin{tabular}{lcccc}
\hline Codes & \multicolumn{3}{c}{ Boy } & \multicolumn{3}{c}{ Girl } \\
\cline { 2 - 5 } & $\mathbf{f}$ & $\mathbf{\%}$ & $\mathbf{f}$ & $\mathbf{\%}$ \\
\hline Designing a Device or Robot & 7 & 70.0 & 1 & 25.0 \\
3D-Production & 5 & 50.0 & 0 & 00.0 \\
Coding & 2 & 20.0 & 1 & 25.0 \\
Robotic Coding & 1 & 10.0 & 1 & 25.0 \\
Total & 15 & 100 & 3 & 100 \\
\hline
\end{tabular}

In Table 5, when the students' drawings regarding robotic coding were examined according to their gender, it was seen that both boys and girls generally design a device or robot and 3D-Production. Below were also the examples of students' drawings with their explanations (Figure 5-8).

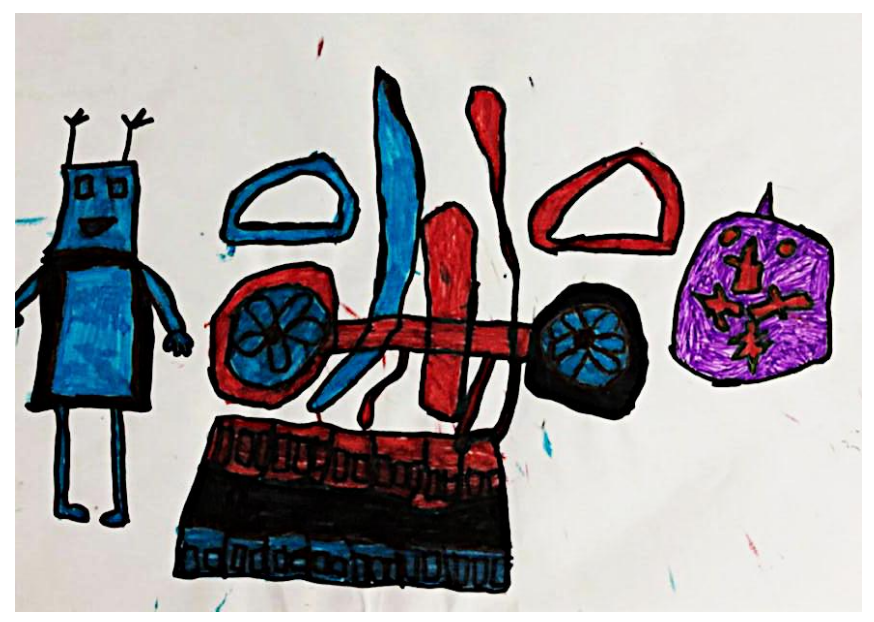

Figure 5. “...I can produce the parts I want....The 3D-printer is a useful device...I produce parts for my car and mount them." (Boy, Age:8).

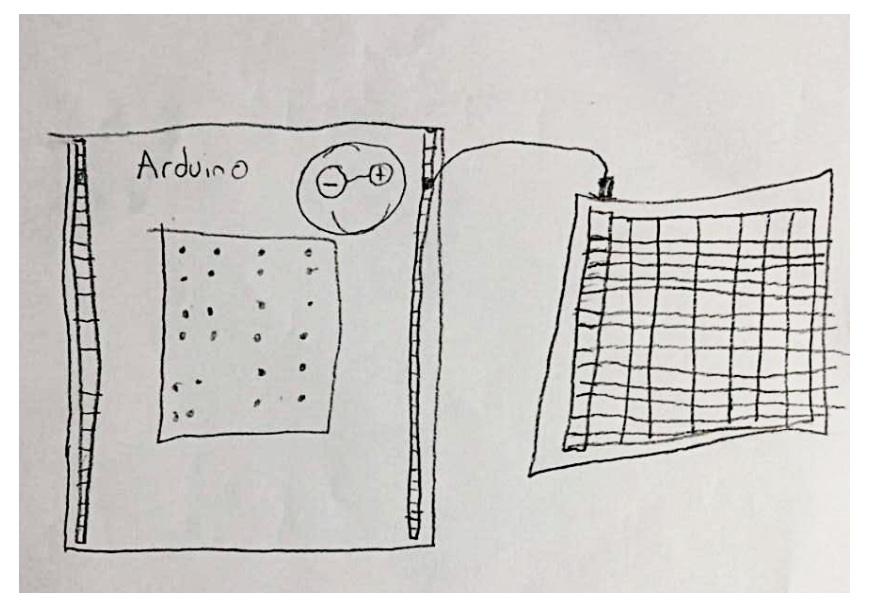

Figure 6. "I connect my tablet with the cable to the Arduino, and with the codes, I check and move the Arduino parts from the tablet, or I can light up." (Girl, Age:9). 


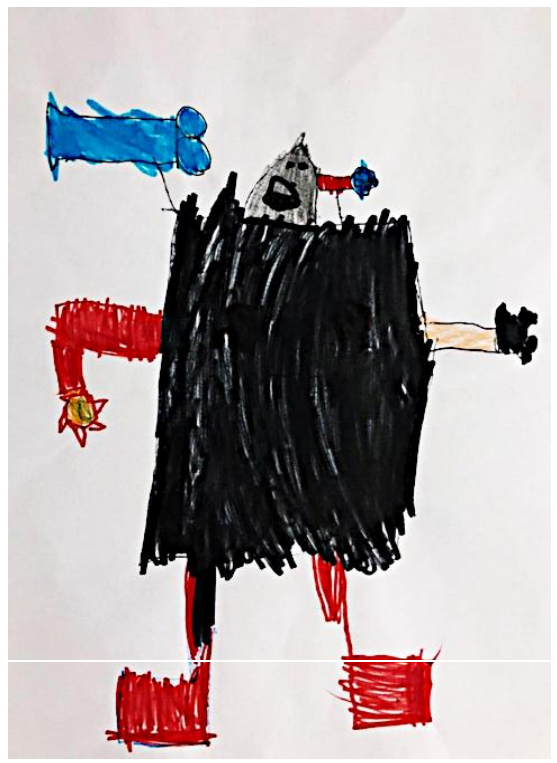

Figure 7. “...I designed a robot. It detects codes with the object on its head, it goes when I press forward....This robot can do what I say." (Boy, Age:7).

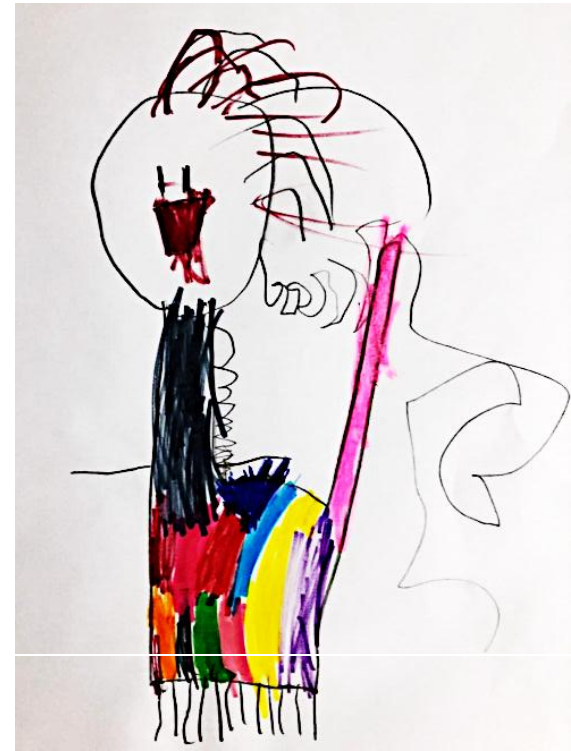

Figure 8. "I can make a colorful robot with my 3D-printer pen..." (Girl, Age:7).

The analysis of children's drawings demonstrated that robotic coding education was reflected in the students' drawings as they learned the skills such as constructing different circuits during the education they received, designing small-scale robotic circuits using various sensors, designing with a 3D-printer pen and various applications, and producing the objects in three dimensions.

\section{Discussion}

This study revealed the perceptions of primary school students about robotic coding by drawings who have received robotic coding education. It was determined that most of the students drew robots related to the concept of robotic coding. In addition to drawing robots, they drew tablets, 3D-printers, cars, computers, headphone and Arduino set, respectively.

Drawing can be considered as an expression activity in which children can reflect their inner worlds, freely draw what they don't say and express their thoughts. Pictures made by children provide detailed clues about their perception of life (Yavuzer, 2000). However, Ersoy and Türkkan (2009) emphasized the importance and necessity of conducting interviews to support children's paintings. Therefore, in the current study, besides the drawings of the students, their explanations about the drawings were also included. Although it was not clear from their drawings that some students stated they drew 3D-printers in their drawings.

Paintings or drawings made by children are an important tool for us to understand their thoughts and personality traits. According to Yavuzer (2013), there are differences in the paintings of children who have and do not have a sense of self-confidence and adequacy in terms of whether they can draw themselves, and to create compositions with the colors they use and the figures they draw. In the present study, it was determined that $80 \%$ of the participating students did not include themselves in their drawings. Although two boys included themselves in their drawings, none of the girls did. The low number of students who draw themselves in their drawings may mean that the students participating in the robotic coding training do not develop enough self-confidence and sense of competence in robotic coding. The informal robotic coding education that students received for the first time in their lives may not have been enough for them to feel as a part of robotic coding.

It has been observed that the majority of students draw inanimate objects such as "robot" and "3Dprinter" in their drawings, and only a few included living beings. It seems that robotic coding 
education may not have adequately linked robotic coding with daily life. On the other hand, Chen et al. (2017) emphasized that it is important to develop the links between the robotic programming environment in the curriculum and everyday reasoning. In addition, individual studies in robotic coding education, usually using computers, tablets, robots, Arduino sets, electrical cables, etc., or informal education given in classes of seven or eight may limit the social development of students.

In the present study, it has been observed that the majority of students add human and living features such as face, hand to the robots they drew. It was also reported that anthropomorphism, which can be defined as the loading of human features to inanimate objects, is frequently seen in young children, and that anthropomorphism decreases as children grow up, but some children are resistant to this change (Kallery \& Psillos, 2004; Kattmann 2008; Byrne, Grace, \& Hanley, 2009). Furthermore, it was observed that girls used colors more than boys in their drawings. Likewise, Hall (2008) stated that the reason for girls to have more colors and decorations in their drawings in the study of the communication skills of 56-71 months old children was due to the fact that girls experience more aesthetic anxiety than boys.

In literature, there are many studies investigating the effect of robotics on computational thinking skills of students (Sullivan, 2008; Atmatzidou, \& Demetriadis, 2016; Chalmers, 2018). Robots in education effectively combine STEM concepts, coding, computational thinking, and engineering skills in learning all the knowledge and skills necessary for students to be successful in the future. The educational robot is an all-in-one technological learning tool that supports the future success of students and needs to be increasingly integrated into school curricula (Eguchi, 2014). Jaipal-Jamani and Angeli (2017) point out that robotics can provide opportunities even for primary school students to learn STEM concepts earlier than expected, and that these robotic learning experiences can improve students' confidence and interest in mathematics, science and engineering.

\section{Recommendations}

This study can be repeated with a larger study group in different age groups. In addition, different methods and techniques can be used to collect data other than the draw-and-explain method.

\section{References}

Atalay, N., Anagün, S, S., \& Kumtepe. E. G. (2016). Evaluation of technology integration in science teaching with 21st century skills: A slowmation application. Bartin University Journal of Faculty of Education, 5(2), 405-424.

Atmatzidou, S., \& Demetriadis, S. (2016). Advancing students' computational thinking skills through educational robotics: A study on age and gender relevant differences. Robotics and Autonomous Systems, 75, 661-670.

Byrne, J., Grace, M., \& Hanley, P. (2009). Children's anthropomorphic and anthropocentric ideas about micro-organisms: Educational research. Journal of Biological Education, 44(1), 37-43.

Çağlltay, K., Cạııroglu, J., C,ăğıltay, N., \& Cạkıroglu, E. (2001). Teachers' perspectives about the use of computers in education. Hacettepe University Journal of Education, 21(21), 19-28.

Campbell, C., \& Walsh, C. (2017). Introducing the 'new' digital literacy of coding in the early years. Practical Literacy: The Early and Primary Years, 22(3), 10-12.

Chalmers, C. (2018). Robotics and computational thinking in primary school. International Journal of Child-Computer Interaction, 17, 93-100.

Chen, G., Shen, J., Barth-Cohen, L., Jiang, S., Huang, X., \& Eltoukhy, M. (2017). Assessing elementary students' computational thinking in everyday reasoning and robotics programming. Computers $\mathcal{E}$ Education, 109, 162-175. 
Eguchi, A. (2014, July). Robotics as a learning tool for educational transformation. In Proceeding of 4th international workshop teaching robotics, teaching with robotics $\mathcal{E} 5$ th international conference robotics in education Padova (Italy) (pp. 27-34).

Ersoy, A., \& Türkkan, B. (2009). Perceptions about Internet in elementary school children's drawings. Elementary Education Online, 8(1), 57-73.

García-Carrillo, C., Greca, I. M., \& Fernández-Hawrylak, M. (2021). Teacher perspectives on teaching the stem approach to educational coding and robotics in primary education. Education Sciences, 11(2), 64 .

Hall, E. (2008, September). My brain printed it out! Drawing, communication, and young children: A discussion. In British Educational Research Association Annual Conference, Heriot-Watt University, Edinburgh (pp. 3-6).

Jaipal-Jamani, K., \& Angeli, C. (2017). Effect of robotics on elementary preservice teachers' selfefficacy, science learning, and computational thinking. Journal of Science Education and Technology, 26(2), 175-192.

Kallery, M., \& Psillos, D. (2004). Anthropomorphism and animism in early years science: Why teachers use them, how they conceptualise them and what are their views on their use. Research in Science Education, 34(3), 291-311.

Kattmann, U. (2008). Learning biology by means of anthropomorphic conceptions? In M.Hammann, M. Reiss, C. Boulter, \& S. D. Tunnicliffe (Eds.), Biology in context: Learning and teaching for the twenty-first century (pp. 7-17). London: Institute of Education.

López, J. M. S., Otero, R. B., \& García-Cervigón, S. D. L. (2021). Introducing robotics and block programming in elementary education. RIED. Revista Iberoamericana de Educación a Distancia, 24(1), 95-113.

McWhirter, J. M., Collins, M., Bryant, I., Wetton, N. M., \& Bishop, J. N. (2000). EvaluatingSafe in the Sun', a curriculum programme for primary schools. Health Education Research, 15(2), 203-217.

Miles, M. B., \& Huberman, A. M. (1994). Qualitative data analysis: An expanded sourcebook. sage.

Papavlasopoulou, S., Giannakos, M. N., \& Jaccheri, L. (2019). Exploring children's learning experience in constructionism-based coding activities through design-based research. Computers in Human Behavior, 99, 415-427.

Sáez-López, J. M., Sevillano-García, M. L., \& Vazquez-Cano, E. (2019). The effect of programming on primary school students' mathematical and scientific understanding: Educational use of mBot. Educational Technology Research and Development, 67(6), 1405-1425.

Sayın, Z., \& Seferoğlu, S. S. (2016). Coding education as a new 21st century skill and its effect on educational policies. In Academic Informatics Conference (pp. 3-5).

Sullivan, F. R. (2008). Robotics and science literacy: Thinking skills, science process skills and systems understanding. Journal of Research in Science Teaching: The Official Journal of the National Association for Research in Science Teaching, 45(3), 373-394.

Ulubey, Ö., \& Aykac, N. (2017). Reflections of educational philosophies on the primary school curricula from the foundation of the republic of Turkey to 2005. Mersin University Journal of the Faculty of Education, 13(3), 1173-1202.

White, R. T., \& Gunstone. R. F. (1992). Probing understanding. London: The Falmer Press.

Yavuzer, H. (2000). Resimleriyle çocuk (8thEd.). İstanbul: Remzi Kitabevi.

Yavuzer, H. (2013). Resimleriyle çocuk (17thEd.). İstanbul: Remzi Kitabevi. 